\section{Two African elephant species, not just one}

Your affirmation that the African forest elephant and the African savannah elephant are separate species (Nature 537, 7; 2016) is timely. Earlier this month, the 17th Conference of Parties to the Convention on International Trade In Endangered Species (CITES) rejected a proposal to list all African elephants as one species under CITES Appendix I. The US Fish and Wildlife Service is also reviewing a proposal to change the status of both species from threatened to endangered under the US Endangered Species Act (see go.nature.com/2d2ayzb).

Data supporting the separate taxonomic status of African forest elephants (Loxodonta cyclotis Matschie) and African savannah elephants (Loxodonta africana Blumenbach) have been available for more than a decade. Their evolutionary divergence is comparable in magnitude to that between modern Asian elephants (Elephas) and the extinct mammoths (Mammuthus spp.). Hybridization between the two African species is rare and highly localized and does not affect the genetic integrity of either species (A. L. Roca et al. Nature Genet. 37, 96-100; 2004).

In the past decade, African forest elephant populations have fallen by about $60 \%$ (T. Breuer et al. Conserv. Biol. 30, 1019-1026; 2016). Recognition of the forest elephant and the much more numerous savannah elephant as separate species will help to protect their evolutionary diversity.

Colin P. Groves ${ }^{*}$ Australian National University, Canberra. colin.groves@anu.edu.au ${ }^{*}$ On behalf of 4 correspondents (see go.nature.com/2eye8f5 for full list).

\section{Include social equity in California Biohub}

We have an idea for philanthropists Priscilla Chan and Mark Zuckerberg, who last month announced their first major investment in basic science: US\$600 million for a Biohub in San Francisco, California.

They aspire to 'advance human potential and promote equality' (https://chanzuckerberg.com). As members of the Science FARE (Feminist Anti-Racist Equity) collective, we suggest that 5-7\% of the Biohub's health-research budget should be used to design and monitor goals of justice and equality from the outset. Otherwise, social inequalities could limit the project's potential. Innovative social scientists will need to work with bench scientists, engineers and clinical researchers. Health research should include trained people from all social backgrounds and a variety of disciplines.

The affordability of treatments and access to them is crucial, irrespective of class, gender, race or disabilities. Building equality into Biohub's founding architecture will allow it to be tackled simultaneously with disease eradication, mitigating the uneven social distribution of health care in San Francisco's Bay Area and beyond.

Science FARE ${ }^{\star}$ University of

California, Berkeley, USA.

charis@berkeley.edu

${ }^{\star}$ On behalf of 6 correspondents (see go.nature.com/2drsnmffor full list).

\section{Soil clean-up needs cash and clarity}

China plans to curb soil pollution by 2020 and to bring environmental risks under control by 2030 . In our view, several issues must be addressed for these goals to be realized. Meanwhile, a long-awaited law to prevent soil pollution should be enacted urgently.

The ongoing clean-up requires more funding from local and central government. Polluters should also contribute to remediation costs so that the authorities can decontaminate polluted soil without further liability. Treatment of industrial sites in inland areas should not be overlooked in favour of megacities in eastern China that have a greater potential for property development.

The administration and supervision of operations needs to be streamlined. Although 36 government departments are involved in soil-pollution control, their respective responsibilities are still not fully defined or coordinated. Standardized regulations must be drawn up to aid communication among stakeholders.

Soil and hydrogeological conditions vary enormously across China, calling for a range of different technologies and skills. International expertise and cooperation could help to address the scientific issues and develop efficient clean-up technologies. Changsheng Qu, Shui Wang Iiangsu Academy of Environmental Sciences, Nanjing, China.

Peter Engelund Holm University of Copenhagen, Denmark. 031202026@163.com

\section{Species loss: learn from health metrics}

The inability to quantify which threats matter most across species and ecosystems is a problem for policymaking and resource allocation (see S. L. Maxwell et al. Nature 536, 143-145; 2016). Biodiversity conservation could learn from public-health metrics and go beyond simply counting the number of recorded threats to quantify the contribution of each one to species loss.

Public-health priorities are set using disability-adjusted life years (DALYs), a measure of healthy years of life lost to a disease as a result of death or sickness. DALYs can be compared among diseases, regions or populations; summed to assess total disease impact; and used to evaluate the effectiveness of interventions (C. J. L. Murray et al. Lancet 386, 2145-2191; 2015). The absence of these key functions from existing biodiversity risk assessments limits their usefulness (see, for example, the IUCN Red List).

Although they are not without flaws, DALYs have led to fundamental changes in public health, for example by refocusing efforts on diseases that cause the most harm, such as malaria. They have also prompted reassessment of underlying threats that exacerbate illness, such as malnutrition. And they have highlighted areas in which funding exceeds the share of all DALYs, notably in breast cancer. The availability of an accessible metric, comparable across threats, has also contributed to new funding streams such as the Global Fund to Fight AIDS, Tuberculosis and Malaria.

A comparable metric is urgently needed for more precise analysis of biodiversity threats. Kathryn J. Fiorella Cornell University, Ithaca, New York, USA. Giovanni Rapacciuolo Stony Brook University, New York, USA. Christopher Trisos National Socio-Environmental Synthesis Center, Annapolis, Maryland, USA. kfiorella@gmail.com

\section{Martian dance of fiction and fact}

In marking the H. G. Wells anniversary, you highlight what Carl Sagan dubbed the "dance" between science fiction and science fact (see www.nature. $\mathrm{com} /$ scifispecial).

Wells's The War of the Worlds saw the Martian invasion stopped in its tracks by Earth pathogens (S. J. James Nature 537, 162-164; 2016). Now, almost 120 years after Wells's novel was published, the Mars rover Curiosity may have to be diverted because of fears that Earth microbes on the craft could contaminate possible wet areas - a potential habitat for hypothetical Martian life (Nature 537, 145-146; 2016). Such symmetry.

Jonathan Cowie Leicester, UK. www.concatenation.org/contact. html 